\title{
Copper-catalyzed stereoselective conjugate addition of alkylboranes to alkynoates
}

\author{
Takamichi Wakamatsu, Kazunori Nagao, Hirohisa Ohmiya* and Masaya Sawamura*
}

\author{
Full Research Paper \\ Address: \\ Department of Chemistry, Faculty of Science, Hokkaido University, \\ Sapporo 060-0810, Japan \\ Email: \\ Hirohisa Ohmiya* - ohmiya@sci.hokudai.ac.jp; Masaya Sawamura* - \\ sawamura@sci.hokudai.ac.jp \\ * Corresponding author \\ Keywords: \\ alkylborane; alkynoate; conjugate addition; copper; multisubstituted \\ alkene
}

Beilstein J. Org. Chem. 2015, 11, 2444-2450.

doi:10.3762/bjoc. 11.265

Received: 31 August 2015

Accepted: 25 November 2015

Published: 04 December 2015

This article is part of the Thematic Series "Copper catalysis in organic synthesis".

Guest Editor: S. R. Chemler

(c) 2015 Wakamatsu et al; licensee Beilstein-Institut.

License and terms: see end of document.

\begin{abstract}
A copper-catalyzed conjugate addition of alkylboron compounds (alkyl-9-BBN, prepared by hydroboration of alkenes with 9-BBN-H) to alkynoates to form $\beta$-disubstituted acrylates is reported. The addition occurred in a formal syn-hydroalkylation mode. The syn stereoselectivity was excellent regardless of the substrate structure. A variety of functional groups were compatible with the conjugate addition.
\end{abstract}

\section{Introduction}

Copper-mediated conjugate additions of organometallic reagents to alkynoates are powerful tools for the synthesis of multisubstituted alkenes [1-8]. Because of their broad availability and their compatibility with a multitude of functional groups, organoboron compounds are especially popular organometallic reagents. Recently, Yamamoto and co-workers developed copper-catalyzed conjugate additions of aryl- and allylboron compounds to alkynoates $[9,10]$, but alkylboron compounds have not been used for these methods [11].

As related studies we reported earlier the copper-catalyzed conjugate addition of alkylboranes (alkyl-9-BBN) to imidazole- 2-yl $\alpha, \beta$-unsaturated ketones [12-14] and the copper-catalyzed three-component coupling with alkylboranes, alkynoates, and tributyltin methoxide to form trisubstituted alkenylstannanes [15]. The latter reaction pathway involved Sn-trapping of an alkenylcopper intermediate that was formed through syncarbocupration of an alkylcopper(I) species across the $\mathrm{C}-\mathrm{C}$ triple bond of the alkynoate. We envisioned that 1,2-hydroalkylation of the alkynoates might be possible through protontrapping of an alkenylcopper intermediate.

Herein, we report a copper-catalyzed conjugate addition of alkylboranes to alkynoates, providing a versatile approach to $\beta$-disubstituted acrylates [16-19]. The addition occurred in a 
formal syn-hydroalkylation mode. The syn stereoselectivity was excellent regardless of the substrate structure, and a variety of functional groups were tolerated in both the alkylborane and the alkynoate.

\section{Results and Discussion}

Alkylborane 2a $(0.275 \mathrm{mmol})$, which was obtained via hydroboration of styrene (1a) with the 9-borabicyclo[3.3.1]nonane (9-BBN-H) dimer, and ethyl 3-phenylpropiolate (3a, $0.25 \mathrm{mmol})$ were treated with $\mathrm{CuOAc}(5 \mathrm{~mol} \%), t$-BuOK $(5 \mathrm{~mol} \%), \mathrm{P}(\mathrm{OPh})_{3}(10 \mathrm{~mol} \%)$, and $t-\mathrm{BuOH}(0.25 \mathrm{mmol})$ in 1,4-dioxane $(1.2 \mathrm{~mL})$ at $40{ }^{\circ} \mathrm{C}$ for $12 \mathrm{~h}$. The reaction afforded a formal hydroalkylation product, $\beta$-disubstituted acrylate $4 \mathbf{a a}$ in $99 \%$ isolated yield with $>99 \%$ syn selectivity (Scheme 1 ).

The results of ligand screening for the reaction between $\mathbf{2 a}$ and 3a are summarized in Table $1 . \mathrm{P}(\mathrm{OPh})_{3}$ was the most effective ligand in terms of product yield and syn selectivity (Table 1, entry 1). The use of other monophosphine ligands such as $\mathrm{PPh}_{3}$ and $\mathrm{PCy}_{3}$ or the DPPE bisphopshine was also effective in promotion of the reaction, but resulted in a reduced stereoselectivity (Table 1, entries 2-4). No reaction occurred with $N$-heterocyclic carbenes (NHC) such as IMes or IPr (Table 1, entries 5 and 6). The reaction with (IMes) $\mathrm{CuCl}$ or (IPr) $\mathrm{CuCl}$ complex delivered no reaction product (data not shown). The reaction without a ligand resulted in a significantly decreased product yield while the syn selectivity was fairly high (Table 1, entry 7).

The use of less expensive $\mathrm{CuCl}$ as a copper salt was also effective to produce $4 \mathbf{a a}$ in $90 \%$ yield with $99 \%$ syn selectivity. The reaction using $\mathrm{MeOH}$ as a proton source instead of $t-\mathrm{BuOH}$ caused a drastic reduction in the product yield with the syn selectivity slightly decreased (38\%, syn/anti $97: 3)$. The reduction of the yield might be due to the protonation of an alkylcopper species by the more acidic $\mathrm{MeOH}$ (vide infra). There

Scheme 1: Conjugate addition of alkylborane 2a to alkynoate 3a.

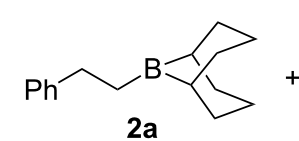

(1.1 equiv)
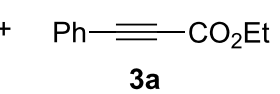

$(0.25 \mathrm{mmol})$

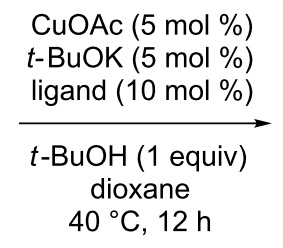
dioxane
$40^{\circ} \mathrm{C}, 12 \mathrm{~h}$

\begin{tabular}{llll}
\hline Entry & Ligand $^{\mathrm{a}}$ & Yield [\%] $^{\mathrm{b}}$ & syn/antic \\
\hline 1 & $\mathrm{P}(\mathrm{OPh})_{3}$ & 99 & $>99: 1$ \\
2 & $\mathrm{PPh}_{3}$ & 99 & $67: 33$ \\
3 & $\mathrm{PCy} 3$ & 56 & $64: 36$ \\
4 & $\mathrm{DPPE}$ & 99 & $83: 17$ \\
5 & $\mathrm{IMes}$ & 0 & - \\
6 & $\mathrm{IPr}$ & 0 & - \\
7 & none & 37 & $97: 3$ \\
\hline
\end{tabular}

aMes: 1,3-bis(2,4,6-trimethylphenyl)imidazole-2-ylidene, IPr: 1,3-bis(2,6-diisopropylphenyl)imidazole-2-ylidene. bYield determined by ${ }^{1} \mathrm{H}$ NMR. CDetermined by ${ }^{1} \mathrm{H}$ NMR or GC analysis of the crude product. 
was no reaction in the absence of a proton sourse. No hydroalkylation product at all could be found when alkyl-9-BBN 2a was replaced by (2-phenylethyl)boronic acid pinacolate ester; the substrates hardly reacted at all.
A variety of $\beta$-disubstituted acrylates were accessible through the hydroboration-conjugate addition one-pot protocol with excellent syn stereoselectivities (Table 2). This protocol tolerated functional groups such as methoxy, ester, phthalimide,

Table 2: Copper-catalyzed conjugate addition of alkylboranes 2 to alkynoates 3 . $^{\text {a }}$

$\mathrm{R}^{1} \curvearrowright$

1

$(9-\mathrm{BBN}-\mathrm{H})_{2}$ dioxane, $60^{\circ} \mathrm{C}, 1 \mathrm{~h}$<smiles>[R]CCB1C2CCCC1CCC2</smiles>

(1.1 equiv)
Alkene<smiles>C=CCc1ccc(OC)c(OC)c1</smiles>

1

1b

2<smiles>C=CC(C)(C)CC(=O)OC</smiles>

1c

3<smiles>C=CCN1C(=O)c2ccccc2C1=O</smiles>

$4^{\mathrm{d}}$<smiles>C=C(C)c1ccccc1</smiles>

$1 \mathrm{e}$

5<smiles>C1=CCCCC1</smiles>

1a
$3 a$

$3 a$

$3 a$<smiles>CCOC(=O)/C(=C\CCCc1ccc(OC)c(OC)c1)c1ccccc1</smiles>

94 99:1<smiles>C=CCC/C(=C\c1ccccc1/C(=C/C(=O)OCC)CCC(C)(C)CC(=O)OC)c1ccccc1</smiles>

87

99:1

$3 a$<smiles>CCOC(=O)/C=C(\CC(C)c1ccccc1)C(/C=C(\CC)c1ccccc1)C1CCCCC1</smiles>

86

$>99: 1$

3a

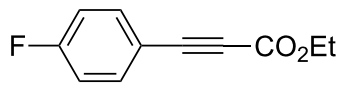

3b
96

98:2
$4 f a$<smiles>CCOC(=CC(=CCc1ccccc1)c1ccc(F)cc1)CC</smiles> 
Table 2: Copper-catalyzed conjugate addition of alkylboranes 2 to alkynoates $3 .^{\text {a }}$ (continued)

7

1a

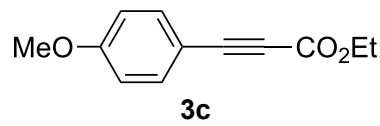

$1 a$

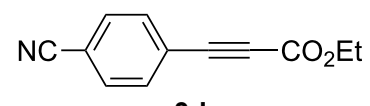

3d

9 1a

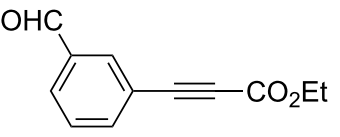

$3 e$

10

1a

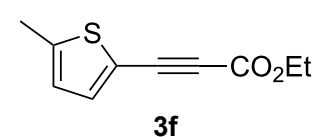

1a

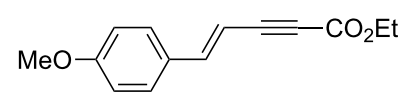

$3 \mathrm{~g}$

1a
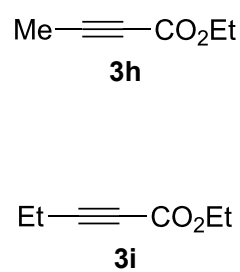

$1 \mathrm{a}$

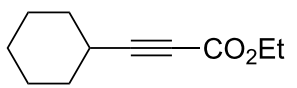

3j<smiles>CCOC(=O)/C=C(\CCc1ccccc1)c1ccc(OC)cc1</smiles>

91 99:1<smiles>CCOC(=O)/C=C(\CCc1ccccc1)c1ccc(C#N)cc1</smiles>

88 99:1<smiles>CCCC=CC(=O)OCC</smiles>

93 99:1 $\mathrm{Ph}$ $4 a e$<smiles>CCOC(=O)/C=C\CCc1ccccc1</smiles>
94:6 $\mathrm{MeO}$<smiles>Cc1ccc(OCc2ccccc2)cc1</smiles><smiles>C/C=C/C(=C\C(=O)OCC)CCc1ccccc1</smiles>

90 $>99: 1$

$\mathrm{Ph}$ 4ag<smiles>CCOC(=O)/C(C)=C/CCc1ccccc1</smiles>

94 $>99: 1$

\section{4ah}<smiles>CCOC(=CC(CC)CCc1ccccc1)CC</smiles>

98 $>99: 1$

4ai

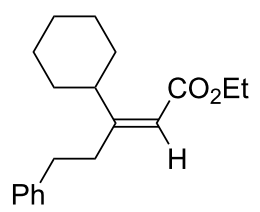

4aj

aThe reaction was carried out with $3(0.25 \mathrm{mmol}), 2(0.275 \mathrm{mmol})$, CuOAc $(5 \mathrm{~mol} \%), t$-BuOK $(5 \mathrm{~mol} \%), \mathrm{P}(\mathrm{OPh}) 3(10 \mathrm{~mol} \%)$ and $t$ - $\mathrm{BuOH}(0.25 \mathrm{mmol})$ in dioxane $(1.2 \mathrm{~mL})$ at $40{ }^{\circ} \mathrm{C}$ for $12 \mathrm{~h}$. Alkylborane 2 was prepared in advance by hydroboration of 1 with the $9-\mathrm{BBN}-\mathrm{H}$ dimer at $60{ }^{\circ} \mathrm{C}$ for $1 \mathrm{~h}$ and used without purification. ${ }^{b}$ Yield of isolated product. ${ }^{c}$ Determined by ${ }^{1} \mathrm{H}$ NMR or GC analysis of the crude product. ${ }^{\mathrm{d} D i a s t e r e m e r i c ~ r a t i o ~(1: 1) . ~}$ 
fluoro, cyano and aldehyde moieties in the alkylboranes and alkynoates (Table 2, entries 1-3, 6-9 and 11).

The data in Table 2 show the variety of functional groups attached to alkylboranes 2 that are tolerated in the reaction. The rather crowded alkylborane $\mathbf{2 c}$, which was prepared from tertiary alkyl substituted terminal alkene $1 \mathbf{c}$, reacted nicely (Table 2 , entry 2). $\beta$-Branched alkylborane $\mathbf{2 e}$, prepared from $\alpha$-methylstyrene (1e), provided $4 \mathbf{e a}$ in good yield (Table 2 , entry 4). Unfortunately, however, the reaction of secondary alkylboranes made from internal alkenes, did not work (Table 2, entry 5).

The variety of alkynoates used is also shown in Table 2 . The fluoro atom and the methoxy, cyano and aldehyde groups were acceptable as para or meta-substituents on the aromatic ring at the $\beta$-positions (Table 2, entries 6-9). The alkynoate $\mathbf{3 f}$ bearing a 2 -thienyl group at the $\beta$-position is also compatible with the conjugate addition and gave $94 \%$ syn selectivity (Table 2 , entry $10)$. The 1,3 -enyne derivative $\mathbf{3 g}$ reacted regioselectively to afford a conjugated 2,4-dienoate $4 \mathbf{a g}$ in $90 \%$ yield with excellent syn selectivity (Table 2, entry 11).

Alkyl groups were also acceptable as $\beta$-substituent of the alkynoates (Table 2, entries 12-14). Alkynoate $\mathbf{3 h}$ with a methyl group at the $\beta$-position reacted with an excellent stereoselectivity (Table 2, entry 12). The alkynoates with an ethyl (3i) or cyclohexyl group (3j) were also suitable substrates (Table 2, entries 13 and 14).

Alkene hydroboration of $\mathbf{1} \mathbf{k}$ followed by copper-catalyzed intramolecular conjugate addition enabled the formation of the corresponding five-membered carbocycle $4 \mathbf{k}$ in $94 \%$ yield with complete syn selectivity (Scheme 2).

To gain insight into the mechanism of the copper-catalyzed conjugate addition, the reaction between 2a and 3a with $t$-BuOD under the optimum conditions was conducted (Scheme 3). The reaction afforded 4aa-D, which is deuterated at the $\alpha$-position of the carbonyl group $(93 \% \mathrm{D})$. The syn selectivity was slightly decreased due to the deuterium isotope effect: Slower D-trap caused isomerization of organocopper intermediates (vide infra). This experimental result indicates that $t$ - $\mathrm{BuOH}$ acts as a proton source.

A possible mechanism for the present copper catalysis is proposed in Figure 1. An alkoxycopper complex (A) is initially formed by the reaction of $\mathrm{CuOAc}, t-\mathrm{BuOK}$ and $\mathrm{P}(\mathrm{OPh})_{3}$. Boron-to-cupper transmetalation between $\mathbf{A}$ and the alkylborane 2 occurs to form an alkylcopper(I) species (B) and a $t$-butoxyborane (9-BBN-Ot-Bu) [12-15,20-25]. Subsequently, the alkylcopper species B forms a $\pi$-complex (C) with alkynoate 3. Then, syn-carbocupration across the $\mathrm{C}-\mathrm{C}$ triple bond of $\mathbf{C}$ with the assistance of Lewis acidic activation with

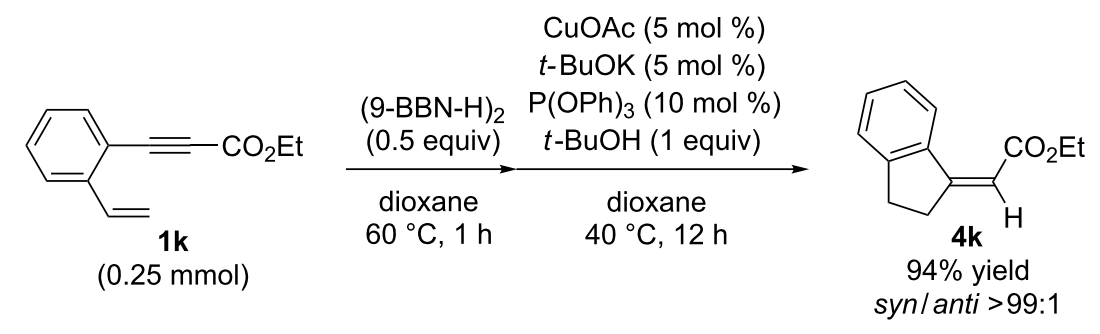

Scheme 2: Synthesis of five membered carbocycle. 
the tert-butoxyborane gave an alkenylcopper intermediate (D). Finally, protonolysis by $t$ - $\mathrm{BuOH}$ produces $s y n-4$, regenerating the alkoxycopper complex A.

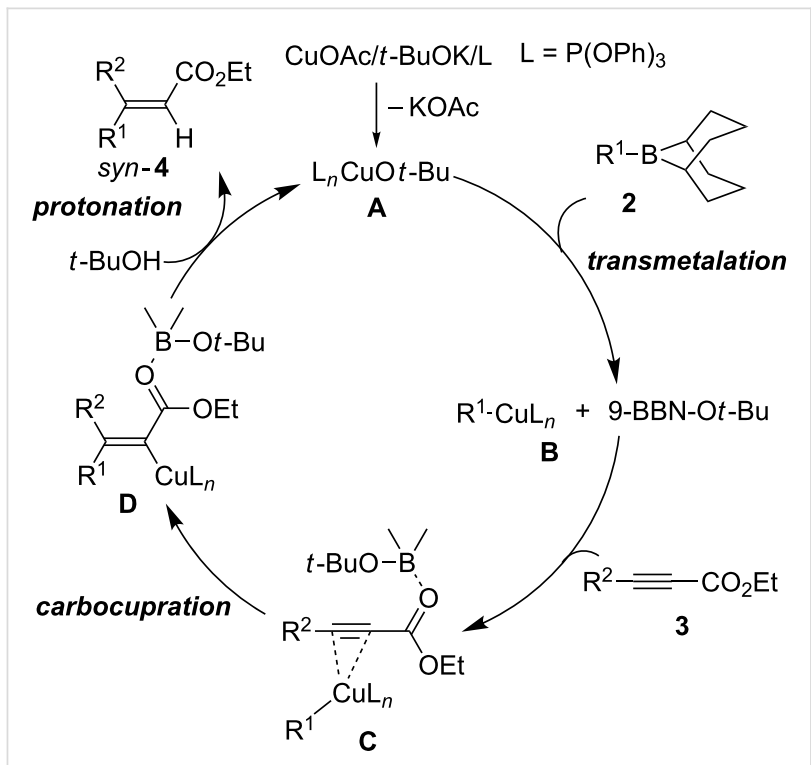

Figure 1: Possible mechanism.

The minor occurrence of anti-addition is likely due to the geometrical isomerization of the alkenylcopper species $\left(\mathbf{D} / \mathbf{D}^{\prime}\right)$ through a copper(I) allenoate complex (E, Figure 2) [15,26] The resulting allenoate $\mathbf{E}$ can undergo protonolysis to form either syn-4 or anti-4 depending on the substituent effects of $\mathrm{R}^{1}$ and $\mathrm{R}^{2}$, while the isomerized alkenylcopper(I) $\mathbf{D}^{\prime}$ should preferentially yield anti-4. The reduction of syn selectivity in the reaction with $\mathrm{PPh}_{3}, \mathrm{PCy}_{3}$ and DPPE may also be due to this isomerization (Table 1, entries 2-4).

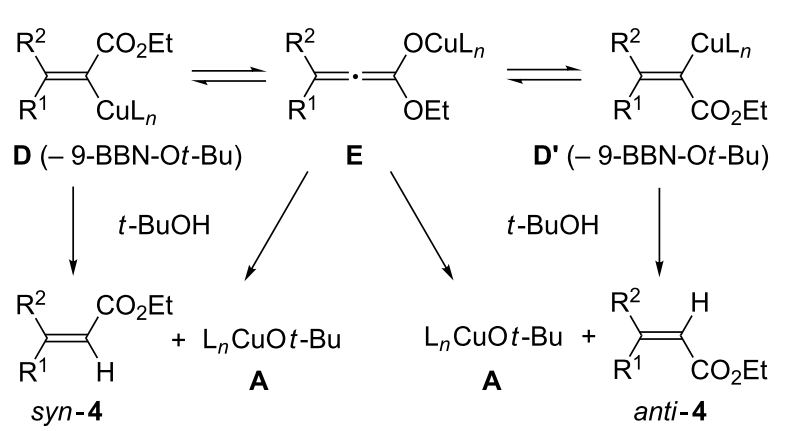

Figure 2: Isomerization of the alkenylcopper intermediates.

\section{Conclusion}

In summary, a copper-catalyzed conjugate addition of alkylboranes (alkyl-9-BBN) to alkynoates to form $\beta$-disubstituted acrylates is reported. The addition occurred in a formal syn- hydroalkylation mode. The stereoselectivity was excellent regardless of the substrate structure. The availability of alkylboranes through in situ alkene hydroboration is an attractive feature of this protocol and various functional groups are tolerated in both the alkylborane and alkynoate substrates.

\section{Experimental}

The reaction shown in Scheme 1 was conducted in a similar manner as described before [15]. Styrene (1a, $33 \mu \mathrm{L}$, $0.289 \mathrm{mmol})$ and $(9-\mathrm{BBN}-\mathrm{H})_{2}(33.6 \mathrm{mg}, 0.138 \mathrm{mmol})$ were placed in a vial containing a magnetic stirring bar. The vial was sealed with a Teflon ${ }^{\circledR}$-coated silicon rubber septum, and the vial was evacuated and filled with argon. 1,4-Dioxane $(0.4 \mathrm{~mL})$ was added to the vial, and the mixture was stirred at $60{ }^{\circ} \mathrm{C}$ for $1 \mathrm{~h}$ to prepare an alkylborane 2a. Meanwhile, CuOAc (1.5 mg, $0.0125 \mathrm{mmol}), \mathrm{P}(\mathrm{OPh})_{3}(6.9 \mu \mathrm{L}, 0.025 \mathrm{mmol})$ and $t$-BuOK (1.4 mg, $0.0125 \mathrm{mmol}$ ) were placed in another vial. The vial was sealed with a Teflon ${ }^{\circledR}$-coated silicon rubber septum, evacuated, and then filled with argon. After 1,4-dioxane $(0.6 \mathrm{~mL})$ was added to the vial, the mixture was stirred at $25^{\circ} \mathrm{C}$ for $1 \mathrm{~h}$. Next, the alkylborane solution was transferred to the vial containing the $\mathrm{Cu}(\mathrm{I})$ complex, followed by the addition of alkynoate $\mathbf{3 a}$ $(41.3 \mu \mathrm{L}, 0.25 \mathrm{mmol})$ and $t$-BuOH $(24 \mu \mathrm{L}, 0.25 \mathrm{mmol})$. After $12 \mathrm{~h}$ stirring at $40{ }^{\circ} \mathrm{C}$, diethyl ether was added to the mixture. The mixture was filtered through a short plug of silica gel, which was then washed with diethyl ether. After the solvent was removed under reduced pressure, flash chromatography on silica gel (0-5\% EtOAc/hexane) provided 4aa (69.4 mg, $0.248 \mathrm{mmol}$ ) in $99 \%$ yield with $>99: 1$ syn/anti selectivity.

\section{Supporting Information}

\section{Supporting Information File 1}

Experimental procedures, spectroscopic and analytical data, and copies of NMR spectra for newly synthesized compounds.

[http://www.beilstein-journals.org/bjoc/content/ supplementary/1860-5397-11-265-S1.pdf]

\section{Acknowledgements}

This work was supported by Grants-in-Aid for Scientic Research (B) (No. 15H03803), JSPS to H.O. and by ACT-C, JST to M.S. and by CREST, JST to M.S. K.N. thanks JSPS for scholarship support.

\section{References}

1. Corey, E. J.; Katzenellenbogen, J. A. J. Am. Chem. Soc. 1969, 91, 1851-1852. doi:10.1021/ja01035a045

2. Siddall, J. B.; Biskup, M.; Fried, J. H. J. Am. Chem. Soc. 1969, 91, 1853-1854. doi:10.1021/ja01035a046 
3. Klein, J.; Turkel, R. M. J. Am. Chem. Soc. 1969, 91, 6186-6187. doi:10.1021/ja01050a047

4. Li, G.; Wei, H.-X.; Whittlesey, B. R.; Batrice, N. N. J. Org. Chem. 1999, 64, 1061-1064. doi:10.1021/jo981976I

5. Yeh, M. C. P.; Knochel, P. Tetrahedron Lett. 1989, 30, 4799-4802. doi:10.1016/S0040-4039(01)80511-6

6. Yamamoto, Y.; Yatagai, H.; Maruyama, K. J. Org. Chem. 1979, 44, 1744-1746. doi:10.1021/jo01324a047

7. Mueller, A. J.; Jennings, M. P. Org. Lett. 2007, 9, 5327-5329. doi:10.1021/ol702546w

8. Jennings, M. P.; Sawant, K. B. Eur. J. Org. Chem. 2004, 3201-3204. doi:10.1002/ejoc.200400314

9. Yamamoto, Y.; Kirai, N.; Harada, Y. Chem. Commun. 2008, 2010-2012. doi:10.1039/b802231c

10. Yamamoto, Y.; Yamada, S.; Nishiyama, H. Chem. - Eur. J. 2012, 18, 3153-3156. doi:10.1002/chem.201103697

11. Rajagopal, T.; Ogilvie, W. W. Synlett 2011, 1113-1116. doi:10.1055/s-0030-1259933

12. Ohmiya, H.; Yoshida, M.; Sawamura, M. Org. Lett. 2011, 13, 482-485. doi:10.1021/ol102819k

13. Yoshida, M.; Ohmiya, H.; Sawamura, M. J. Am. Chem. Soc. 2012, 134, 11896-11899. doi:10.1021/ja304481a

14. Ohmiya, H.; Shido, Y.; Yoshida, M.; Sawamura, M. Chem. Lett. 2011, 40, 928-930. doi:10.1246/cl.2011.928

15. Wakamatsu, T.; Nagao, K.; Ohmiya, H.; Sawamura, M. Angew. Chem., Int. Ed. 2013, 52, 11620-11623. doi:10.1002/anie.201305973

16. Hayashi, T.; Inoue, K.; Taniguchi, N.; Ogasawara, M. J. Am. Chem. Soc. 2001, 123, 9918-9919. doi:10.1021/ja0165234

17. Oh, C. H.; Jung, H. H.; Kim, K. S.; Kim, N. Angew. Chem., Int. Ed. 2003, 42, 805-808. doi:10.1002/anie.200390214

18. Lin, P.-S.; Jeganmohan, M.; Cheng, C.-H. Chem. - Eur. J. 2008, 14, 11296-11299. doi:10.1002/chem.200801858

19. Bush, A. G.; Jiang, J. L.; Payne, P. R.; Ogilvie, W. W. Tetrahedron 2009, 65, 8502-8506. doi:10.1016/j.tet.2009.08.029

20. Ohmiya, H.; Yokobori, U.; Makida, Y.; Sawamura, M. J. Am. Chem. Soc. 2010, 132, 2895-2897. doi:10.1021/ja9109105

21. Nagao, K.; Ohmiya, H.; Sawamura, M. Synthesis 2012, 44 , 1535-1541. doi:10.1055/s-0031-1290818

22. Nagao, K.; Yokobori, U.; Makida, Y.; Ohmiya, H.; Sawamura, M. J. Am. Chem. Soc. 2012, 134, 8982-8987. doi:10.1021/ja302520h

23. Ohmiya, H.; Yokobori, U.; Makida, Y.; Sawamura, M. Org. Lett. 2011, 13, 6312-6315. doi:10.1021/ol202866h

24. Shido, Y.; Yoshida, M.; Tanabe, M.; Ohmiya, H.; Sawamura, M. J. Am. Chem. Soc. 2012, 134, 18573-18576. doi:10.1021/ja3093955

25. Hojoh, K.; Shido, Y.; Ohmiya, H.; Sawamura, M. Angew. Chem., Int. Ed. 2014, 53, 4954-4958. doi:10.1002/anie.201402386

26. Nilsson, K.; Andersson, T.; Ullenius, C.; Gerold, A.; Krause, N. Chem. - Eur. J. 1998, 4, 2051-2058. doi:10.1002/(SICI)1521-3765(19981002)4:10<2051::AID-CHEM2051> 3.0.CO;2-F

\section{License and Terms}

This is an Open Access article under the terms of the Creative Commons Attribution License

(http://creativecommons.org/licenses/by/2.0), which permits unrestricted use, distribution, and reproduction in any medium, provided the original work is properly cited.

The license is subject to the Beilstein Journal of Organic Chemistry terms and conditions:

(http://www.beilstein-journals.org/bjoc)

The definitive version of this article is the electronic one which can be found at:

doi:10.3762/bjoc. 11.265 